\title{
Archivos de museos. Una oportunidad para liderar el conocimiento sobre nuestra historia del arte
}

\author{
MARÍA JOSÉ BADENAS POBLACIÓN \\ Archivo del Museo Nacional de Cerámica y Artes Suntuarias «González Martí»
}

\begin{abstract}
En este artículo se muestra una profunda reflexión de los nuevos espacios de comunicación a los que se enfrenta el documento de los archivos de museos, señalando las incertidumbres a nivel de tratamiento, difusión e investigación de las fuentes documentales archivísticas de los museos cuando se incorporan al espacio de Web. Este artículo surge por la participación active de la autora, archiveras del Museo Nacional de Cerámica y Artes Suntuarias "González Martí" en el proyecto de La Subdirección General de Museos Estatales para el desarrollo e implementación de un micrositio en la web del Ministerio de Cultura y Deporte y un sistema de gestión adecuado para la gestión de esta tipología de archivos.
\end{abstract}

Archivos de Museos, Historia del Arte, Redes de Archivos, Museos de Cerámica

Vivimos en una sociedad global, interconectada y enredada. «Enredada» aquí en su doble acepción: no sólo nos sentimos parte de redes que se entrelazan y nos otorgan un importante valor añadido, ya que si atendemos a la Ley de Metcalfe, el valor de una red es proporcional al cuadrado del número de nodos de esa red. Ahora bien, no se consigue nada si no hay interacciones entre ellos. El valor de la red no deriva de su número de nodos, sino de la intensidad de transacciones entre ellos, (Cornella, 2003, p. 55 ss.). En este contexto, los documentos de archivo a menudo se me representan como piezas de una red (la imagen de «celdillas encadenadas» inspirada en el poema de Nabokov) de las que a su vez surgen nuevas relaciones y sólo vislumbrarlas nos permite conectar y establecer poderosas redes de intercambio de información, fundamentales para reforzar la marca de la institución que representamos. Ahora bien, también a menudo al acceder a Internet sufrimos una fuerte indigestión producida por un exceso de información lo que Alfons Cornella acuñó como «infoxicación» (overload information) (Cornella, 2000) y proyectándose en nuestro cerebro una impresión muy distinta a la de llegar a la verdad, aquí el enredo sería en el sentido de enmarañado, y en muchos casos llevaría a nuestro cerebro al punto de hacernos olvidar qué estábamos buscando.

En el contexto actual, en el que claramente asistimos a un cambio de paradigma del sistema de comunicación, sobrevuela la idea del término phármakon que Platón utiliza para referirse a la creación de la escritura cuando en el Fedro pone en boca de Theuth que la escritura se ha inventado como «fármaco de la memoria y del conocimiento» con su doble significado de veneno y remedio, viendo a la escritura como un remedio para la inmortalidad, y a la vez como un veneno para la oralidad, pues elimina la magia

Bajo el principio de que el acceso abierto a los resultados de investigación acelera el avance del conocimiento, todos los contenidos de la edición electrónica de CLIP se distribuyen bajo una licencia de uso y distribución Creative Commons Reconocimiento-NoComercialCompartirlgual 3.0 España (CC BY-NC-SA 3.0 ES). 
de la interacción entre dos individuos en el aquí y ahora. A mi modo de ver, esa situación tiene un paralelismo perfecto con la comunicación digital.

\section{La comunicación digital, el nuevo phármakon platónico}

Parafraseando a Lledó (2000, p. 53) cuando se refiere a la escritura, diciendo que no sólo fija el lenguaje y conserva lo pensado sobre una superficie material, sino que crea otra forma de comunicación, podríamos sustituir el término escritura por imágenes digitales o contenidos audiovisuales y nos daríamos cuenta de que asistimos a una nueva forma de comunicarnos.

Por lo que se refiere a nuestra área de trabajo, la digitalización de los documentos de los archivos y su salida web es de algún modo nuestro phármakon, (Platón, Fedro, p.142). Por un lado, nos permite superar lo local, trascender al público cercano y ser consultados desde cualquier punto del planeta, nos concede, pues, el don de la ubicuidad a la vez que también nos ofrece cierta inmortalidad. Por otro, en cambio, nos obliga a tomar las medidas oportunas para conjurar el veneno y evitar perdernos en una maraña de datos en el complejo universo de Internet.

Este nuevo sistema de intercambio de datos plenamente digital al que asistimos, nos genera también, como a Platón, nuevos recelos y nuevas respuestas, (Lledó, 1992, 57) que podemos expresar también con este término.

Las imágenes digitales de los documentos de archivo replican una realidad tangible, que si no se identifica y se almacena convenientemente puede perderse en el mar cibernético. Necesitamos evitar estos riesgos y para ello ideamos complejos antídotos, lo que hemos convenido en denominar metadatos. La información contextual que otorgamos a las imágenes se convierte en la pócima secreta para localizar en cualquier momento lo que hemos volcado e incrementar las posibilidades de recuperación de esos objetos digitales es la clave de su futura inmortalidad.

El éxito de los portales web como herramientas para el acceso online 24 horas al día/7 días a la semana o 365 días al año es incuestionable. Es la principal manera de acceder a la información contenida en los archivos en este siglo XXI.

La pregunta que nos surge es ¿cómo llegamos desde los archivos a la salida web? Conviene señalar, por si algún despistado crédulo e ingenuo no lo tenía claro aún, que no todo el patrimonio documental que atesoramos en nuestros archivos está accesible online, y tal vez, ni siquiera el 20\%. 


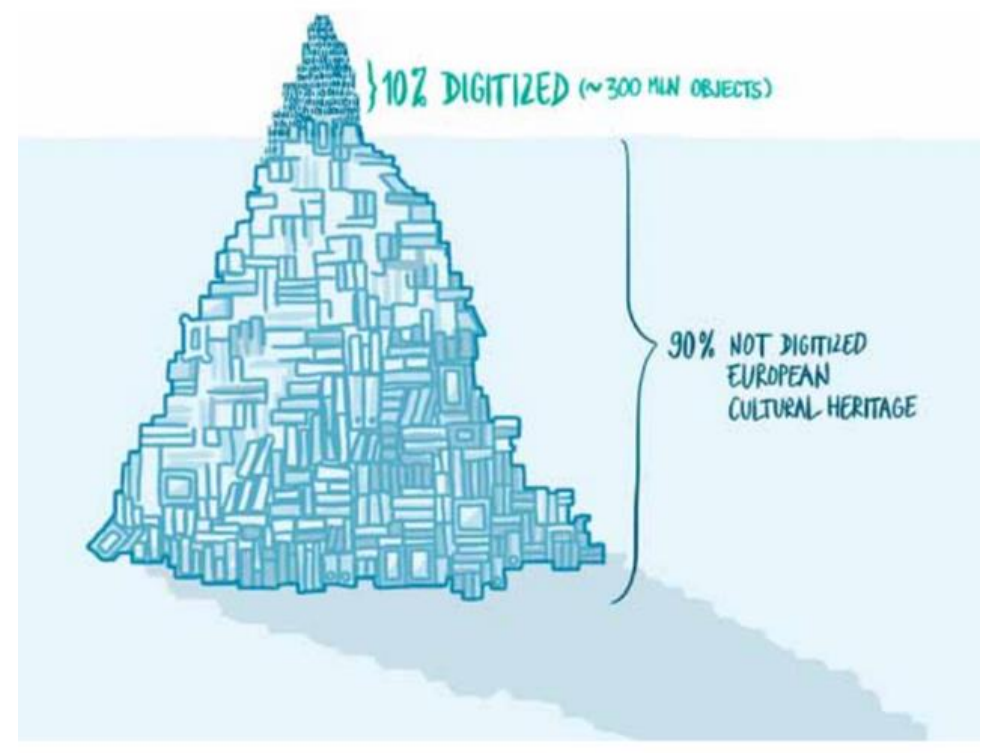

Figura 1:

El 90\% del patrimonio documental europeo todavía no ha sido digitalizado. Este 10\% disponible representa 300 millones de objetos, de los cuales solo una tercera parte (34\%) está actualmente (septiembre de 2015) disponible online.

Visual: Elco van Staveneren, www.denkschets.nl, CC BY-SA.

En el informe We transform the world with culture. Strategy Europeana 2015-2020 de Europeana se presentaba este gráfico tan elocuente (fig. 1), donde se muestra que a pesar del gran número de objetos digitales accesibles desde su portal en 2015 ni siquiera representaba el 10\% del total. Tal vez las tareas previas a la digitalización, tan costosas, no sólo en recursos económicos, sino también en conocimientos específicos, no tienen la repercusión viral que tiene la carga de imágenes en un portal, y posiblemente ese es uno de los motivos de su descuido. Afrontar este reto debe ser una constante en los archivos históricos. Desde estas líneas, querría insistir en la necesidad de llegar a la salida web en perfectas condiciones con los pasos previos sólidamente ejecutados:

1. Espacios de conservación y unidades de instalación adecuadas según la materialidad de los documentos a conservar. Se requerirán materiales de conservación secundaria de buena calidad y pensando en el largo plazo. Lo que se custodia en los archivos históricos ya no está sometido a ninguna calificación de futuro, es incuestionablemente de conservación permanente.

2. Importante paso, asignar una denominación unívoca a cada documento de archivo. Es decir, concederle una numeración, signatura, id, número de control, que nos permita localizarlo y diferenciarlo del resto sin lugar a dudas.

3. Inventario / descripción de las unidades documentales, es posiblemente el punto clave para la posterior recuperación de la información. Momento de crear los puntos de acceso, las autoridades oportunas que nos permitirán en el futuro acceder a ellos, recordemos que se trata de esa importante información contextual que se convierte en el antídoto efectivo al veneno de la maraña y la infinitud de Internet.

4. Digitalización masiva. Es habitual que en la calle se oigan las maravillas de la digitalización sin más, cuando a menudo no se sabe que una buena digitalización debe ir precedida de una buena ordenación. En el caso de digitalizar el caos, el resultado es meramente un caos digital. 
Aterrizando en este último punto conviene traer a colación la definición de digitalización tomada del Real Decreto 4/2010 del Esquema Nacional de Interoperabilidad, donde se le asocia este significado: «proceso tecnológico que permite convertir un documento en soporte papel o en otro soporte no electrónico en uno o varios ficheros electrónicos que contienen la imagen codificada, fiel e íntegra del documento»

Interesa destacar estos tres calificativos: codificada, fiel e íntegra, por lo que una imagen capturada con nuestro móvil de una parte de un documento no sería fiel e íntegra, y como tal no se ajustaría a esta definición. Siguiendo con las características de las imágenes digitales de los documentos de archivo, vamos ahora a la Guía de Digitalización publicada por el Ministerio de Hacienda y Administraciones Públicas (Guía, 2a . ed, 2016) toda imagen digital debe constar de los siguientes componentes:

i. Imagen electrónica.

ii. Metadatos mínimos obligatorios que tiene todo documento electrónico y, en función de las necesidades específicas de cada organización, metadatos complementarios para su gestión.

iii. Si procede, firma electrónica, que avala la integridad del resultado de la aplicación del proceso de digitalización y que se aplicaría mediante alguno de los sistemas de firma electrónica previstos en los artículos 42 y 43 de la Ley 40/2015, de 1 de octubre.

Publicar en portales web es una excelente manera de acercar la cultura a todos los ciudadanos, los datos del acceso de la población a Internet no dejan de crecer, e incluso las franjas de edad que permanecían al margen en plena pandemia se han incorporado como usuarios habituales.

Llegados a este punto, ya sabemos que cualquier plan de digitalización sin ordenación previa de los materiales a digitalizar y en perfectas condiciones de conservación, así como sin una carga de metadatos contextuales que nos permitan localizar las imágenes digitales en cualquier momento, se convierte más en un veneno que en un remedio, y un plan de digitalización que no tenga como finalidad última la salida web y facilitar el acceso a todos los ciudadanos tampoco lo sería plenamente. Esto nos lleva a otra cuestión: ¿basta con digitalizar? Llenar la red de objetos digitales a menudo genera confusión al usuario final que recibe una avalancha de datos sin contextualizar. Fruto de esta necesidad se trabaja intensamente en el desarrollo de una nueva norma de descripción archivística impulsada desde el Consejo Internacional de Archivos con la denominación Records in Context (RiC) (Consejo Internacional de Archivos, 2019). Mientras eso llega, querría romper una lanza a favor de Wikipedia, esa enciclopedia universal completamente altruista y anónima, con información de gran calidad, contrastada y de algún modo proyectada y prefigurada sin imaginarlo en la ficción de Borges (1944, pp. 7-15) «Tlön, Uqba, Orbis Tertius», donde siempre desde el juego de lo no-real, se habla de aquel lugar donde «no existe el concepto del plagio: se ha establecido que todas las obras son obra de un solo autor, que es intemporal y es anónimo».

Wikipedia es una realidad poderosa que contextualiza y expone en artículos de considerable extensión contenidos de todo tipo, es justo decir que se nutre de fuentes fiables y seguras y se constituye, aunque algunos se empeñen en esconderlo, como el punto de partida de cualquier investigación, es una primera puesta en antecedentes. Las obras de referencia que ocupaban los primeros estantes de todas las bibliotecas públicas, han sido reemplazadas por esta obra magna, siempre en construcción y en eterna actualización, que cuenta con un ejército de voluntarios, altruistas del conocimiento, que ni siquiera buscan el reconocimiento público, y ponen a nuestra disposición contenidos mascados y digeribles, con la posibilidad de ir a más, de profundizar y de acceder a fuentes primarias.

Desde los archivos, no debemos descuidar la formación activa de nuestro público, las actividades educativas dirigidas a las jóvenes generaciones es una tarea inaplazable que tiene como función básica el aprendizaje sobre los valores trascendentales de los documentos para comprender la historia, por lo que es fundamental mantener la importancia de las asignaturas de Historia en los currículums académicos de primaria y secundaria, puesto que el único y verdadero modo de preservar el patrimonio histórico es 
hacer que los más jóvenes lo conozcan y sepan de su existencia. No se quiere lo que no se conoce, esta es una piedra angular para la conservación de nuestro patrimonio.

La colaboración, las interrelaciones y la proyección desde nuestro entorno local hasta lugares inhóspitos e inexplorados son constantes de nuestro presente y los archivos no son ajenos a esta realidad, por lo que los objetivos de todo archivo histórico hoy día deben pasar por la salida web en portales específicos que den acceso a sus datos. Son muchos ciudadanos los que afirman, y no les falta razón, que si algo no sale como resultado de una búsqueda de Google, no existe.

\section{Estamos asistiendo a una suerte de positivismo posmoderno}

Los portales de archivos son siempre espacios donde informarse de manera segura y de calidad. Ahora bien esta barra libre de documentos de archivo convierte en potenciales historiadores a todos los ciudadanos, lo que conlleva el riesgo manifiesto de una suerte de positivismo posmoderno. Me refiero a esa tendencia de usar y reutilizar los documentos de archivo como contenedores de información sin aplicarles ningún tipo de crítica textual, y a menudo también con cierto desconocimiento sobre las herramientas necesarias para llegar siquiera a comprender documentos medievales y modernos escritos a veces en latín, o castellano antiguo, o en cualquier otra de las lenguas peninsulares, y con tipos gráficos que poco se parecen a nuestras amadas Arial o Times New Roman.

Es innegable que asistimos a un momento histórico en el que a golpe de clic y sin moverse de casa se tiene acceso a un mayor número de documentos de archivo, muy probablemente el sueño inconfesado de Leopold von Ranke, y de este monumento al documento para probar hechos (Le Goff, 1991, p. 227), que además en sus orígenes implicaba una serie de conocimientos eruditos para comprender el propio documento y aplicarle la correspondiente crítica textual. En la actualidad esta posibilidad se desvanece casi por completo y de ésta deriva la segunda etiqueta que otorgamos al término, con la sensación común de que los documentos se descontextualizan de sus coordenadas espacio-tiempo e incluso de sus propios protagonistas y de los acontecimientos en qué surgieron para servir de cualquier manera a cualquier uso.

Echo de menos un tratamiento de los documentos de archivo con oficio de historiador, ahora mismo el acceso masivo a los fondos de los archivos es algo tremendamente inesperado y brutal. Hace tan solo 15 años, un historiador dedicado a una investigación tenía que desplazarse obligatoriamente hasta el archivo en cuestión donde posiblemente se confinaría durante semanas y localizase con suerte apenas dos documentos de interés para su tema de investigación. Los investigadores se han acomodado a las nuevas condiciones de esta sociedad de la sobre-información, y la visita a los archivos se sustituye por una intensa búsqueda en Google, no hay que engañarse. Por lo que conseguir que nuestros portales salgan en los primeros lugares de los resultados de las búsquedas de Google sería una buena baza.

\section{Caminando hacia la red de Archivos de Museos Estatales}

En todo este contexto de presencia digital y salida web, descubrimos que en los Museos Estatales hay archivos históricos todavía inéditos, que aguardan salir de la caverna para llenar de luz nuestra historia del arte. Ya en 2013 en un artículo publicado en El profesional de la información se apuntaban las grandes posibilidades (Varela, 2013, 235) de los archivos históricos de los museos para profundizar en el conocimiento y estudio de las colecciones museográficas.

Desde la Subdirección General de Museos Estatales del Ministerio de Cultura y Deporte se ha emprendido un camino ilusionante en este sentido que permitirá conectar los archivos de los museos con sus colecciones museográficas a la vez que permitirá establecer interacciones entre los diferentes museos que constituyen la red de Nuestros Museos constituida por: Museo Nacional de Antropología, Museo del 
Traje, Museo de América, Museo Nacional de Artes Decorativas, Museo Sorolla, Museo Cerralbo, Museo Romántico, Museo Arqueológico Nacional, Museo Nacional de Arte Romano, Museo Nacional de Escultura, Casa Cervantes, Museo Nacional de Cerámica y Artes Suntuarias González Martí, Museo Nacional de Arqueología Subacuática, Museo y Centro Nacional de Investigación de Altamira, Museo Sefardí y Museo del Greco.

La creación de esta Red de Archivos de Museos Estatales nace con la finalidad de crear un marco de trabajo que favorezca la mejora y la optimización de recursos materiales y humanos de sus archivos e impulse el trabajo cooperativo, impulsando el gran potencial de este patrimonio documental que conservan los museos estatales. Entre otros muchos aspectos, destacamos como objetivos de la Red, tomando como referencia el Real Decreto 1708/2011, de 18 de noviembre, por el que se establece el Sistema Español de Archivos y se regula el Sistema de Archivos de la Administración General del Estado y de sus Organismos Públicos y su régimen de acceso:

- Fomentar la cooperación y la coordinación entre los archivos de museos que la integran.

- Posicionar a los archivos de los museos estatales como centros de referencia para el estudio de la museología y la museografía de estas instituciones.

- Garantizar la accesibilidad del patrimonio documental a la ciudadanía.

- Diseñar líneas de actuación que tengan como fin último el incremento, conservación, preservación, investigación y difusión del patrimonio documental.

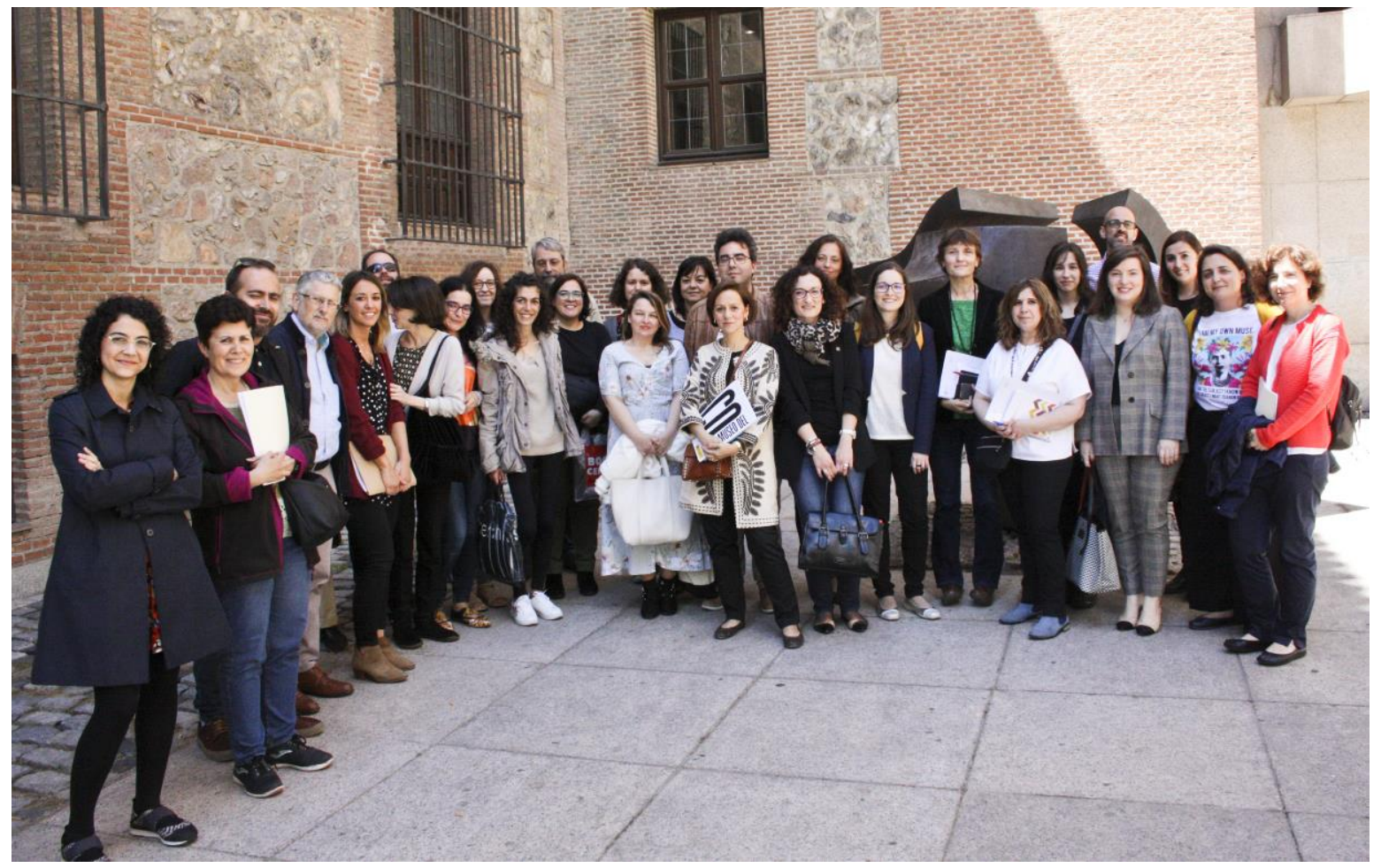




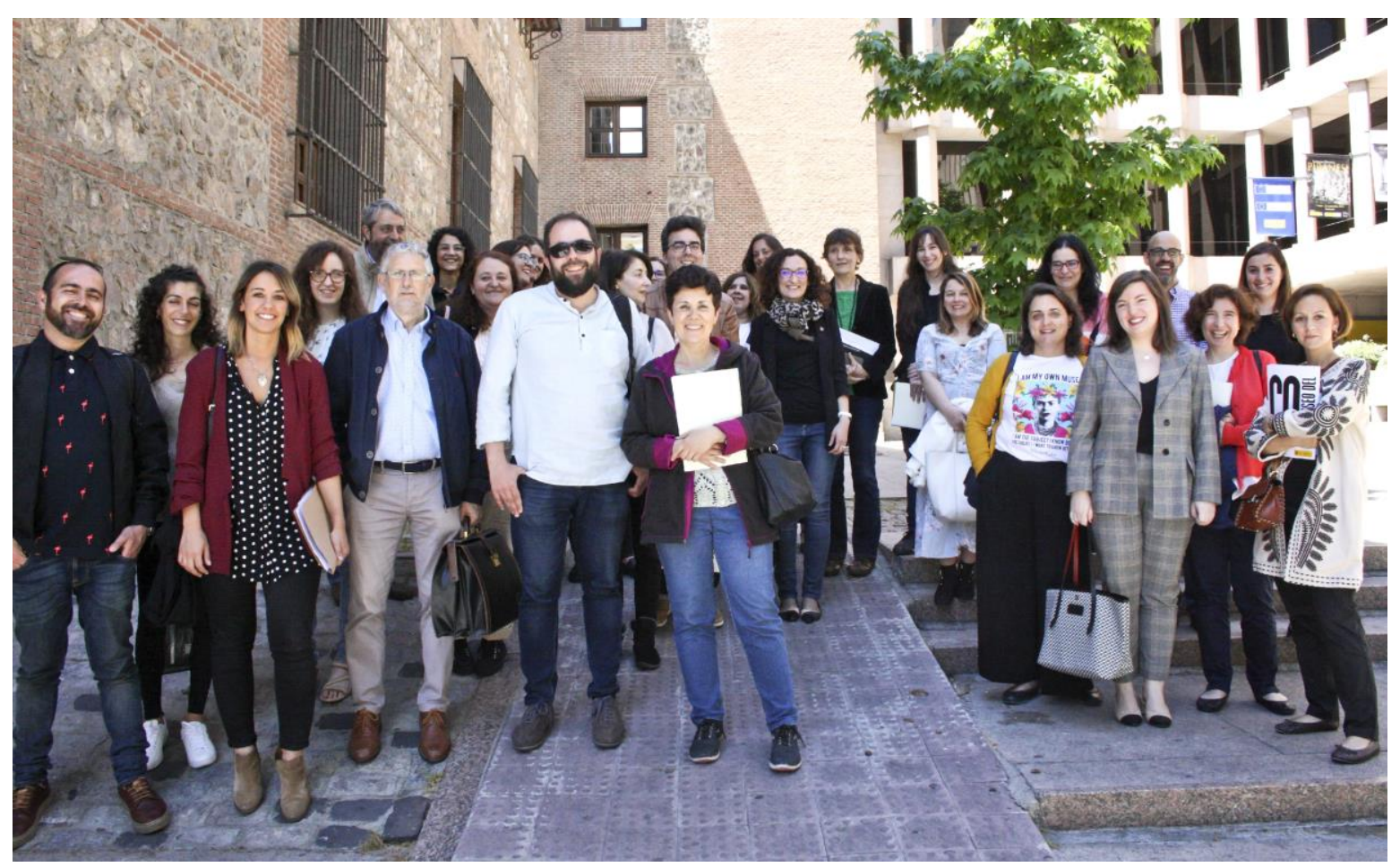

Figura 2 y 3 :

Fotografías tomadas a 10 de mayo de 2019. Reunión de inicio de la futura red de Archivos de Museos (Archimus). Autor: Fabián Álvarez Martín

Sede del Ministerio de Cultura y Deporte, Plaza del Rey, s/n

El pasado 10 de mayo de 2019 la Subdirección General de Museos Estatales celebró una primera reunión (fig. 2 y 3) en la sede del Ministerio de Cultura y Deporte (Plaza del Rey, Madrid) con presencia de todos los técnicos de documentación de museos y los técnicos de archivo de museos bajo la coordinación de la jefa del área de Colecciones, Reyes Carrasco Garrido, que supuso el pistoletazo de salida a esta red. En las actas de la mencionada reunión se recoge de manera formal la constitución de la red de Archivos de Museos, con la denominación definitiva de Archimus.

La Subdirección General de Museos Estatales está trabajando desde este momento muy intensamente para el desarrollo e implementación de un micrositio en la web del Ministerio de Cultura y Deporte y un sistema de gestión adecuado para cubrir las necesidades del material de archivo. Con la finalidad de agilizar y avanzar al mejor ritmo posible en este proyecto se han propuesto varios grupos de trabajo que funcionan a pleno rendimiento, con la finalidad de contribuir a reforzar la imagen de marca de nuestros museos. Esta apuesta por poner en valor los archivos de los museos contribuirá a desvelar aspectos todavía inéditos de la memoria de nuestros museos y sus colecciones.

Desde el Archivo del Museo Nacional de Cerámica para celebrar este año el Día Internacional de los Archivos (9 de junio de 2020), que precisamente tenía como leitmotiv «Empowering archives» la capacidad de los archivos como depósitos de memoria para liderar las actuales sociedades del conocimiento, elaboró un contenido audiovisual que evidenciaba cómo una parte de los documentos del Archivo del Museo Nacional de Cerámica establecieron en su momento redes reales de intercambio de información (fig. 4). 


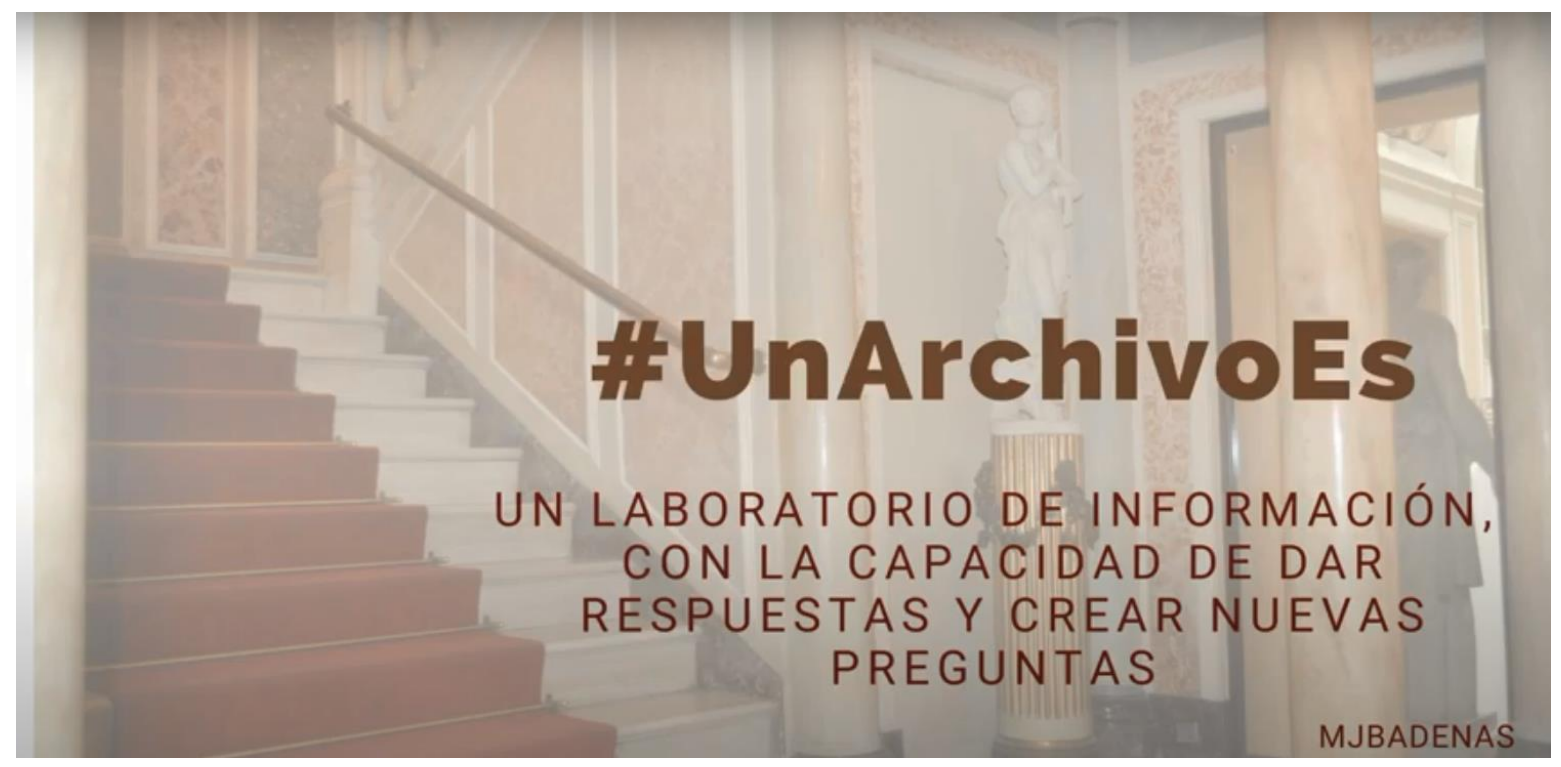

Figura 4:

Vídeo de \#UnArchivoEs para la celebración del Día Internacional de los Archivos, a 9 de junio de 2020. https://www.youtube.com/watch?v=hEVHzcDog8Q

Los fondos documentales de todas las instituciones siempre responden a afianzar el concepto de identidad y también la trazabilidad del desempeño público, pues como sabemos el término «archivo» en su origen tiene la doble acepción de principio, comienzo y mando, orden, ejercicio de poder.

En la realización de este contenido audiovisual se destacaron las relaciones establecidas por el Museo Nacional de Cerámica con otras instituciones internacionales dedicadas también al estudio de la cerámica, con la finalidad de fortalecer esos lazos que ya antaño fueron objeto de una intensa correspondencia.

Esas instituciones seleccionadas para la confección de este material de difusión son el Museo internazionale delle ceramiche en Faenza, cuyo fundador, Gaetano Ballardini (1878-1953), guarda un gran paralelismo con el mismísimo Manuel González Martí (1877-1972), fundador del Museo Nacional de Cerámica. Único en su género, el Museo de Faenza fue adquiriendo prestigio a nivel internacional. En 1926 ofrecía no sólo colecciones antiguas, sino también célebres piezas de fábricas de cerámica europea y de los ceramistas contemporáneos más cotizados. Durante la Segunda Guerra Mundial el Museo sufrió daños por el bombardeo de 13 de mayo de 1944. Ballardini reabrió de nuevo en 1949 y precisamente unos pocos años después (1954) González Martí inauguraba el actual Museo Nacional de Cerámica.

También se conserva correspondencia con otra institución internacional de reconocido prestigio, la Hispanic Society of America, fundada por Archer Milton Huntington (1870-1955) el 18 de mayo de 1904. La fluidez del intercambio epistolar entre Manuel González Martí (1877-1972) y Archer Huntington primero, así como su nombramiento como cuarto vice-presidente en 1957 y el intercambio posterior mantenido con Anna Hyatt Huntington (1876-1973) desvelan una relación prolífica entre casi estrictos contemporáneos.

Por último, se destaca en el audiovisual la conexión con la Academia Internacional de Cerámica (AIC), proyectada en 1953 por Henry J. Reynaud, director del Musée suisse de la céramique et du verre y presidente de la AIC hasta su muerte en 1964. La Academia sigue convocando anualmente un congreso y en su Asamblea General reúne tanto a representantes de los museos nacionales como a organizaciones culturales y en calidad de asesores a alfareros, artistas, diseñadores, escritores, coleccionistas, galeristas, restauradores y comisarios artísticos. 
A modo de conclusión, queremos abogar por hacer realidad que los archivos sean espacios dinámicos y abiertos, que conjuren esa imagen de lugares oscuros, donde discurre un tiempo lento. Los archiveros debemos contribuir a romper los muros no tanto físicos como mentales que a menudo se levantan entre el público y su patrimonio documental y salir a comunicar para en definitiva poner al servicio de los ciudadanos el patrimonio que les pertenece, y hacer realidad el lema de la medalla del Cuerpo Facultativo: Sic vos, non vobis.

\section{Bibliografía}

Borges, Jorge Luis, Tlön, Uqbar, Orbis tertius, Ficciones, 1944, 7-15 pp.

Carruthers, Mary, Le livre de la mémoire. La mémoire dans la culture médiévale. Mácula, collection Argo, París, $2002,428 \mathrm{pp}$.

Consejo Internacional de Archivos, Records in Contexts. A conceptual model for archival description, diciembre 2019, 97 pp.

Cornella, Alfons, Infoxicación: buscando un orden en la información, 2003, 125 pp.

Cornella, Alfons. "Nuevos instrumentos contra la infoxicación". ExtraNet. Revista de Infonomía: La información en las organizaciones, 2000.2 Consultado en: http://www.quadernsdigitals.net/index.php?accionMenu=hemeroteca.VisualizaArticuloIU.visua liza\&articulo id $=3901$

Dirección de Tecnologías de la Información y las Comunicaciones (DTIC), Subdirección General de Información, Documentación y Publicaciones (coord.) Guia de aplicación de la Norma Técnica de Interoperabilidad de Digitalización de documentos, $2^{\mathrm{a}}$ ed., julio de 2016, NIPO: 630-16-336-2.

Europeana Foundation, Transforming the world with culture: Next steps on increasing the use of digital cultural heritage in research, education, tourism and the creative industries, White Paper, 2015, $31 \mathrm{pp}$.

Lledó, Emilio, El surco del tiempo, Barcelona, Crítica, 1992, 231 pp.

Le Goff, Jacques, Capítulo III «Documento/Monumento», El orden de la memoria. El tiempo como imaginario, Paidós, Barcelona, 1991, p. 227

Platón; Moreschini, Claude; Vicaire, Paul, Phèdre. Bilingüe, Les Belles Lettres, París, 2002, 238 pp.

Varela Agüí, Enrique. «Documentación y acceso a las colecciones y bibliotecas de los museos estatales de España» El profesional de la información, 2013, mayo-junio, v.22, n.3. ISSN: 1386-6710, pp. 233239.

\section{Autora:}

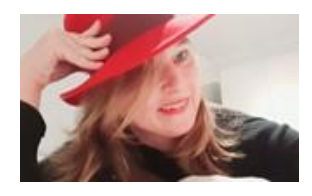

MARÍA JOSÉ BADENAS POBLACIÓN

Facultativa de Archivos del Museo de Cerámica y Artes Suntuarias "González Martín"

Trabajó en el Archivo General de la Administración (Alcalá de Henares), cuando ingresó en el Cuerpo Facultativo de Archiveros, luego se incorporó en el Museo de Cerámica y Artes Suntuarias (Valencia) como Jefa del Archivo. Es docente de la Universidad de Valencia. 